\title{
More about Aldabra
}

THE war between the Royal Society and the British Ministry of Defence over the proposed airfield on the island of Aldabra in the Indian Ocean has persuaded the Royal Society to take the unusual step of sending a delegation to the ministry to plead the case for the total preservation of the island. The President of the Royal Society, Professor P. M. S. Blackett, led a delegation of his colleagues to the ministry on May 22. From what went on it is plain that the ministry has not yet decided whether an airfield will be placed on the island but that alternative sites in the Indian Ocean have been ruled out. The Secretary of State for Defence, Mr Denis Healey, says in a statement released after the meeting that he will see that the scientific issues are fairly presented to his colleagues and that if a decision is taken to go ahead with building an airfield and harbour on the island "we will ensure that the scientific bodies concerned are fully and continuously consulted about the way in which the decision is implemented".

The Royal Society's case against the building of an airfield on Aldabra is supported by a scientific memorandum which rehearses not merely the arguments against gross interference with Aldabra but also the record of how other intrusions by human activity have in the past damaged isolated ecosystems like that now threatened.

The memorandum points out that oceanic islands differ in fundamental respects from continental areas. The floras and faunas found on them necessarily represent those few species with efficient long-range dispersal mechanisms which may be quite insignificant in a mainland setting. Whole groups of continental dominants may be absent. Apart from bats, land mammals have not reached true oceanic islands. Amphibia, freshwater fishes and many orders of insects are lacking. The interaction between the various species and groups is of particular interest to ecologists, and the Royal Society points out that the Galapagos Islands provided Darwin with precisely this kind of insight. The existence on oceanic islands of specialized species-birds which do not fly, for example-and of relict species whose range has been reduced to that of a single island, is another scientific benefit to be found on oceanic islands.

But isolation is also a protection. "Drastic ecological changes would occur if the few species capable of colonizing oceanic islands were required to compete with the more varied species from the mainland."

Among the reef islands in the Indian Ocean, Aldabra is the largest and the richest. The Royal Society's memorandum points out that the island supports 400 species of insects compared with 65 on Assumption Island, 37 on Cosmoledo, 63 from Farquhar and 22 from Providence. Aldabra has a dozen native land birds compared with half that number on Assumption. To some extent Aldabra (like Farquhar) has been protected by its lack of guano. At Farquhar, however, natural vegetation has been cleared for plantation and cats, rats, goats and rabbits have been introduced. Aldabra remains unique because the giant land tortoises which have disappeared from neighbouring islands still persist, as do the species of flightless rail no longer to be found on Assumption, Cosmoledo and Astove.

The Royal Society memorandum continues with a detailed description of the ecology of the island (see Nature, $213,1174 ; 1967)$. It argues that the interest of Aldabra rests on the fact that it is an elevated atoll rather than a sea-level atoll, which means that it has a wider range of habitats than is usually the case. Among elevated atolls, it is closest to continental land, which again makes for diversity. Proximity to Africa means an exceptionally rich collection of unique species-10 per cent of the plants are found nowhere else-and there are endemic crustaceans, a mollusc, a fruitbat, and even a freshwater fish. The island is one of the two great breeding grounds in the Indian Ocean for the green turtle and is distinguished by the absence of human settlement.

The Royal Society has a gloomy tale to tell about the effects of human settlement elsewhere on oceanic islands. The construction of airfields and military establishments on remote islands since the Second World War "has provided a great deal of information on the ways in which these modify island ecosystems". Profound and often irreversible changes in the ecology are said often to be the consequence. For example, the memorandum records the disappearance of the Cordia forest on Canton Island following the building of an airstrip in 1939. The native flora, then only 14 species, now numbers more than 150. At Tern Island in the French Frigate Shoals, five species of vascular plants have now been joined by 18 new species. At Wake Island, there were 13 species of plants in 1841, 18 in 1923, and more than 90 in the 1950s. The memorandum also points out that the Marshall Islands have been similarly joined by exotic species from elsewhere.

The introduction of exotic species of animals seems to lead to more drastic consequences. The endemic flightless rail at Wake Island became extinct during the siege in the Second World War and other species of flightless rail have disappeared from other islands in the Pacific. The memorandum says that "the breeding colonies of the Laysan albatross, Diomedea immutabilis, on Sand Island, Midway Atoll, in the Pacific, represent the classic case of competition between birds and aeroplanes". One-third of the entire population of this species nests at Midway and continues to do so even though half the area of Sand Island is occupied by airport installations. Between ten and twenty per cent of the breeding population seems now to be killed each year by aircraft-18,000 in January 1964, for example. Nobody seems satisfied with the efficacy of the steps taken to reduce the interaction between aircraft and birds.

On Aldabra, the Royal Society is concerned that the breakdown of isolation will itself be damaging. However, damming the lagoon and restricting water circulation will affect the ecology of the lagoon mangroves and of bird species which now feed on lagoons at low water. The large-scale removal of vegetation to build a runway will kill off some animals. Sewage disposal, oil waste and the use of pesticides could harm all kinds of animals from tortoises and sea-birds to the microfauna.

And then there is the problem of noise and its effect on the ibis and the flamingo, the indiscriminate or accidental killing of wild life as well, the possibility that the control of sea-birds should be thought necessary, and the risk of fire.

In general, the Royal Society takes the line that the well-documented experience of the disruption of island ecosystems in other parts of the world makes it clear that "any development of Aldabra must cause serious scientific loss". While acknowledging that if development does take place on the island, rigorous steps should be taken to minimize the interference and disruption there will be, the Royal Society emphasizes that "no amount of conservation planning and forethought could avoid the loss of the major contribution which the study of Aldabra can make to science-a contribution that can be made only by total preservation of the island for long-term studies". 